\title{
Condições higiênicas sanitárias da carne de sol comercializada no município de Cruz das Almas, Bahia e deteç̧ão de cepas com resistência antimicrobiana
}

\section{Hygienic sanitary conditions of sun dried meat marketed in Cruz das Almas, Bahia and detection of strains with antimicrobial resistance}

\author{
Norma Suely Evangelista-Barreto ${ }^{1 *}$; Priscila Coutinho Miranda ${ }^{2}$; Danillo Cerqueira \\ Barbosa $^{3}$; Ricardo Henrique Bastos de Souza ${ }^{4}$; Marly Silveira Santos ${ }^{5}$
}

\begin{abstract}
Resumo
Este trabalho objetivou avaliar a qualidade microbiológica e físico e química da carne de sol comercializada no município de Cruz das Almas, Bahia, bem como traçar o perfil de resistência das estirpes isoladas frente a diferentes fármacos comerciais. Foram analisadas 36 amostras de carne de sol, adquiridas em 12 estabelecimentos (supermercados, minimercados, açougues e mercado municipal) e quantificadas bactérias mesófilas aeróbias, coliformes, Staphylococcus coagulase positiva, presença de E. coli e Salmonella spp., bem como determinado o teor de umidade, atividade de água $\left(\mathrm{A}_{\mathrm{w}}\right)$ e cloreto. Em $83 \%$ dos estabelecimentos a contagem de bactérias mesófilas foi $>10^{5} \mathrm{UFC}_{\mathrm{g}} \mathrm{g}^{-1}$ e em $58 \%$, coliformes a $35^{\circ} \mathrm{C}$ foi $>10^{5}$ NMP.g- ${ }^{1}$ e coliformes a $45^{\circ} \mathrm{C}>10^{3} \mathrm{NMP}{ }^{-1}$. Escherichia coli foi isolada em $75 \%$ dos estabelecimentos. Staphylococcus spp. variou de $4,8 \times 10^{4}$ a $9,0 \times 10^{8}$ UFC.g $^{-1}$, não sendo isolado Staphylococcus coagulase positiva. Salmonella foi encontrada em $25 \%$ dos estabelecimentos. A umidade na carne de sol variou de 52,37 a $74,69 \%$, a $\mathrm{A}_{\mathrm{w}}$ de 0,87 a 0,95 e o cloreto de 3,16 a $5,98 \%$. Salmonella foi $100 \%$ resistente à tetraciclina, ácido nalidíxico, cefalotina e eritromicina, com resistência intermediária à ampicilina e gentamicina. Escherichia coli foi resistente a eritromicina $(100 \%)$; ampicilina (68,7\%); cefalotina (71,4\%); tetraciclina $(64,2 \%)$; ácido nalidíxico $(35,7 \%)$ e gentamicina $(12,5 \%)$. Cepas de E. coli multirresistentes foram observadas em $87,5 \%$ dos isolados, sendo que em $28,6 \%$ a resistência foi mediada por plasmídio. Perfil de multirresistência foi observado em todas as salmonelas, com uma estirpe apresentando resistência plasmidial. A comercialização da carne de sol em Cruz das Almas apresenta falhas higienicossanitárias em virtude da elevada carga microbiana. Tal fato compromete a inocuidade e vida útil do produto, podendo ainda servir de risco para a saúde pública, visto a veiculação de estirpes com resistência antimicrobiana.
\end{abstract}

Palavras-chave: Coliformes, contaminação, comercialização, segurança alimentar

${ }^{1}$ Eng $^{a}$ de Pesca, Prof ${ }^{a}$ Dr $^{a}$ do Programa de Mestrado em Microbiologia Agrícola, Universidade Federal do Recôncavo da Bahia, UFRB, Cruz das Almas, BA. E-mail: nsevangelista@ufrb.edu.br

2 Eng $^{\circ} \mathrm{Agr}^{\circ}$, Discente do Programa de Mestrado em Microbiologia Agrícola, UFRB, Cruz das Almas, BA. E-mail: pcoutinhomiranda@ yahoo.com.br

${ }_{3}^{3}$ Discente do curso de Licenciatura em Física, UFRB, Amargosa, BA. E-mail: danillo1987@hotmail.com

${ }^{4}$ Eng $^{\circ}$ de Pesca, UFRB, Cruz das Almas, BA. E-mail: ricardo.fiperj@gmail.com

${ }^{5}$ Nutricionista, Discente do Programa de Mestrado em Microbiologia Agrícola, UFRB, Cruz das Almas, BA. E-mail: marly.nutr@ gmail.com

* Autor para correspondência 


\begin{abstract}
This study aimed to evaluate the microbiological, physical and chemical qualities of sun dried meat marketed in Cruz das Almas, Bahia, as well as trace the resistance profile of the isolated strains against different commercial pharmacos. There were collected and analysed 36 samples of sun dried meat, acquired in 12 different establishment (supermarkets, mini-markets, butchers and a municipal market), and quantified mesophilic aerobic bacteria, coliforms, Staphylococcus coagulase positive, E. coli and presence of Salmonella spp., as well as specific content humidity, water activity $\left(\mathrm{A}_{\mathrm{w}}\right)$ and chloride. In $83 \%$ of the establishments, mesophilic bacteria counted $>10^{5} \mathrm{CFU} \cdot \mathrm{g}^{-1}$ and $58 \%$ coliforms at $35^{\circ}$ $\mathrm{C}>10^{5} \mathrm{NMP}^{-g^{-1}}$ and coliforms at $45^{\circ} \mathrm{C}>10^{3} \mathrm{NMP}^{-1}$. Escherichia coli was isolated in $75 \%$ of the establishments. Staphylococcus spp. ranged from $4.8 \times 10^{4}$ to $9.0 \times 10^{8} \mathrm{UFC}^{-1} \mathrm{~g}^{-1}$, not being isolated Staphylococcus coagulase positive. Salmonella was found in $25 \%$ of the establishments. The humidity in the sun dried meat samples ranged from $52.37 \%$ to $74.69 \%$, the $\mathrm{A}_{\mathrm{w}}$ from 0.87 to 0.95 and the chloride from $3.16 \%$ to $5.98 \%$. Salmonella was $100 \%$ resistant to tetracycline, acid nalidixic, cephalothin and erythromycin, with intermediate resistance to ampicillin and gentamicin. Escherichia coli was resistant to erythromycin (100\%), ampicillin (68.7\%), cephalothin (71.4\%), tetracycline $(64.2 \%)$, nalidixic acid $(35.7 \%)$ and gentamicin (12.5\%). Multiresistant strains of E. coli were observed in $87.5 \%$ of the isolates, and it happened that in $28.6 \%$ of the resistance it was mediated by plasmids. Multidrug resistance profile was observed in all Salmonella, with a strain showing plasmid resistance. The marketing of sun dried meat in Cruz das Almas presents hygienic and sanitary failures due to it's high microbial loads. This fact undermines the safety and product lifetime, and may also pose risk to public health since it markets strains with antimicrobial resistance.
\end{abstract}

Key words: Coliforms, contamination, commercialization, food safety

\section{Introdução}

A carne de sol é um produto artesanal, resultante de técnicas superficiais de salga e desidratação normalmente empregada pela população do norte e nordeste do Brasil. A ausência de tecnologias sofisticadas para a sua elaboração, bem como padrões oficiais de identidade e qualidade permite que a produção, comercialização e distribuição do alimento ocorram em condições higiênicossanitárias precárias, permitindo a veiculação de microorganismos patogênicos e colocando em risco a saúde dos consumidores (MENUCCI et al., 2010).

Um dos fatores determinantes para a elevada carga microbiana encontrada na carne de sol é o baixo teor de sal utilizado, suficiente apenas para reduzir a atividade de água para valores próximos a 0,96 , valor esse capaz de inibir o crescimento de Pseudomonas, mas que oferece condições favoráveis ao desenvolvimento de bactérias Gram-positivas, como as pertencentes ao gênero Staphylococcus. A carne de sol apresenta condições propícias ao desenvolvimento de Staphylococcus aureus, não somente por suas características intrínsecas supracitadas, mas, principalmente, pelas condições em que o produto é comercializado (VIGNOTO; CARMO; WOSIACKI, 2010).

A determinação de micro-organismos deteriorantes e patogênicos na carne de sol serve de base para estabelecer padrões microbiológicos, bem como de subsídio para que haja adequação tecnológica no processamento desse alimento. Para isso, as bactérias do grupo dos coliformes, principalmente a bactéria Escherichia coli, tem sido usada como o indicador de contaminação fecal mais conhecido. A importância das bactérias em relação à carne acontece, principalmente, pelo fato das mesmas estarem intimamente ligada ao processo de deterioração, infecção e intoxicação alimentar (FRANCO; LANDGRAF, 2008).

A contagem total das bactérias mesófilas de um produto é utilizada como indicativo do histórico da manipulação a que foi submetido, com reflexo na qualidade da matéria prima empregada, bem como no tempo de prateleira do produto final (COSTA; SILVA, 2001). 
As carnes e seus derivados situam-se entre os alimentos que mais preocupa a humanidade, em razão dos riscos que oferecem. Nos Estados Unidos, durante o período de 2009 a 2010, dos 790 surtos causados por um único agente etiológico Salmonella foi o segundo micro-organismo mais envolvido, respondendo por $30 \%$ dos surtos, além de Escherichia coli enteropatogênica. A carne de origem bovina esteve implicada em 13\% dos surtos (MMWR, 2013).

Atualmente, devido à relevância de estudos relacionados ao desenvolvimento da resistência bacteriana, a maioria das investigações sobre transferência de resistência de bactérias de animais para o homem, tem sido relacionados com as bactérias Gram-negativas causadoras de infecções alimentares, como os gêneros Salmonella e Escherichia. Estes micro-organismos estão entre os quatro grupos de bactérias que têm sido alvos prioritários em programas de monitoramento relacionados a esta questão (VIEIRA et al., 2010). Em humanos, linhagens patogênicas de $E$. coli têm sido identificadas como a causa primária de infecções no trato urinário, meningite neonatal, septicemia nosocomial e enterites. Enquanto, resistência a pelo menos uma classe de antimicrobianos tem sido relatada, tanto na medicina humana quanto na veterinária, restringindo as opções terapêuticas disponíveis (SCHMIDT; CARDOSO, 2003).

Em virtude da inexistência de padrões estabelecidos por meio de uma legislação, a carne de sol é encontrada nos mercados com quantidades variadas de cloreto de sódio e umidade, fazendo com que tenham variação na qualidade sensorial, nutricional e principalmente microbiológica. Neste contexto, considerando os riscos que esse produto pode oferecer à saúde da população, em virtude das precárias condições higiênicossanitárias em que a mesma é produzida e comercializada nos diferentes estabelecimentos comerciais de Cruz das Almas, Bahia, é que se buscou analisar a qualidade microbiológica, parâmetros físico e químicos, além do perfil de suscetibilidade antimicrobiana das estirpes isoladas.

\section{Material e Métodos}

O estudo foi realizado na cidade de Cruz das Almas, Bahia, durante o período de dezembro de 2009 a março de 2010. O cálculo do tamanho da amostra ocorreu de forma aleatória simples, de modo que fosse observado o maior número possível de estabelecimentos, localizados na área central do município. Ao todo 14 estabelecimentos comercializavam carne de sol, sendo escolhidos $12(86 \%)$ para o estudo (quatro supermercados, três mini-mercados, três açougues e dois boxes no mercado municipal).

Como a carne de sol é comercializada a granel, foi dispensada amostragem estatística, sendo procedida a colheita de amostra indicativa, aplicando-se um plano amostral de duas classes, que considera a unidade amostral analisada como aceitável ou inaceitável para determinado micro-organismo, quando comparada ao limite de tolerância M para a amostra indicativa (BRASIL, 2001). Assim, de cada estabelecimento foram colhidas três unidades amostrais da carne de sol, pesando cada uma entre 100 e $150 \mathrm{~g}$, totalizando 36 amostras e analisadas no laboratório de Microbiologia de Alimentos e Ambiental, no Núcleo de Estudos em Pesca e Aquicultura na Universidade Federal do Recôncavo da Bahia. Foram pesquisados os seguintes bioindicadores: bactérias mesófilas aeróbias, coliformes a $35^{\circ} \mathrm{C}$, coliformes a $45^{\circ} \mathrm{C}$, presença de E. coli e os patógenos Staphylococcus coagulase positiva e Salmonella (ICMSF, 2006).

Para as análises microbiológicas, a unidade analítica de cada amostra por estabelecimento consistiu na elaboração de um "pool" das três amostras. Para a pesquisa de mesófilos, coliformes e Staphylococcus coagulase positiva, foi utilizado um total de $25 \mathrm{~g}$ da amostra, transferida para um frasco Erlenmayer contendo $225 \mathrm{~mL}$ de solução salina $0,85 \%$, homogeneizado em liquidificador sanitizado, correspondendo à diluição inicial $10^{-1}$. A partir desta, foram realizadas as demais diluições até $10^{-5}$. Para o teste de presença/ausência de 
Salmonella também foram pesados $25 \mathrm{~g}$ da amostra. Todas as análises seguiram a metodologia proposta por Silva et al. (2007).

Para a contagem de bactérias mesófilas aeróbias, alíquotas de 1,0 mL de cada diluição foram semeadas em placas de Petri utilizando a técnica pour plate e adicionado $15 \mathrm{~mL}$ do meio Plate Count Agar (PCA). Após a solidificação do meio, as placas foram incubadas por 48 horas a $35^{\circ} \mathrm{C}$. Decorrido esse período as placas que apresentavam entre $25 \mathrm{e}$ 250 colônias foram contadas, com o auxílio de um contador de colônias, sendo calculado o resultado em unidades formadoras de colônias por grama de $\operatorname{amostra}\left(\mathrm{UFC} \cdot \mathrm{g}^{-1}\right)$.

A determinação do Número Mais Provável $\left(\mathrm{NMP}^{-1} \mathrm{~g}^{-1}\right.$ de coliformes a $35^{\circ} \mathrm{C}$ e a $45^{\circ} \mathrm{C}$ foi realizada usando a técnica de fermentação dos tubos múltiplos. Alíquotas de $1 \mathrm{~mL}$ da amostra foram inoculadas em Caldo Lauril Sulfato Triptose (CLST) contendo tubos de Durhan invertidos e incubados por 48 horas a $35^{\circ} \mathrm{C}$. Em seguida, um inóculo dos tubos positivos (formação de gás nos tubos de Durhan e turvação do meio) foi transferido para tubos contendo Caldo Lactose Bile Verde Brilhante (CBVB) e caldo Escherichia coli (EC) e incubados respectivamente a $35^{\circ} \mathrm{C}$ por 48 horas e a $45^{\circ} \mathrm{C}$ em banho-maria por 24 horas. Dos tubos de EC positivos semeou-se no meio Agar Eosina Azul de Metileno (EMB) e incubou-se a $35^{\circ} \mathrm{C}$ por 24 horas. As colônias características de E. coli foram isoladas em tubos de ensaio contendo Agar Triptose Soja (TSA) inclinado para posterior identificação bioquímica do IMViC (Indol, Vermelho de Metila, Voges-Proskauer e Citrato de Simmons).

A contagem de Staphylococcus coagulase positiva foi realizada por meio da semeadura em superfície no meio seletivo Ágar BairdParker e incubação a $35^{\circ} \mathrm{C}$ por 48 horas. Para a contagem presuntiva do gênero Staphylococcus, foram selecionadas placas contendo de 20 a 250 colônias e contadas as colônias atípicas e típicas (colônias negras, circulares, brilhantes, pequenas, lisas, convexas, com bordas perfeitas e rodeadas por uma zona opaca e ou/ halo transparente). Em seguida, foram retiradas cinco colônias suspeitas de Staphylococcus e submetidas ao teste de coagulase. Para isso, as cepas foram inoculadas em tubos de ensaio contendo $2 \mathrm{~mL}$ de Caldo Infusão Cérebro Coração (BHI) e incubados a $35^{\circ} \mathrm{C}$ por 24 horas. Posteriormente, foram transferidos $0,2 \mathrm{~mL}$ da cultura e adicionado $0,5 \mathrm{~mL}$ de Plasma de Coelho (Larboclin $\left.{ }^{\circledR}\right)$. Os tubos foram homogeneizados levemente e incubados a $35^{\circ} \mathrm{C}$ durante um intervalo de seis horas até 24 horas para a verificação da formação ou não de coágulo.

Para a pesquisa de Salmonella, $25 \mathrm{~g}$ da amostra foi submetida a um pré-enriquecimento em meio BPW (Água Peptonada Tamponada) e incubada a $35^{\circ} \mathrm{C}$ por 24 horas. Decorrido esse período, foram retiradas alíquotas de $1 \mathrm{~mL}$ e $0,1 \mathrm{~mL}$ e inoculadas em $10 \mathrm{~mL}$ de caldo Tetrationato (TT) e $10 \mathrm{~mL}$ de caldo Rappaport (RV), e incubados por 24 horas a $37^{\circ} \mathrm{C}$ e $41,5^{\circ} \mathrm{C}$, em banho-maria, respectivamente. Em seguida, foram retiradas alíquotas com o auxílio de uma alça de níquel-cromo e estriadas em placas de Petri contendo os meios seletivos Agar MacConkey e Agar Salmonella-Shigella (SS) e incubadas por 24 horas a $35^{\circ} \mathrm{C}$. As colônias com crescimento característico de Salmonella nos meios seletivos foram inoculadas em Agar Ferro Açúcar Triplo (TSI) e Agar Lisina Ferro (LIA) e incubados por 24 horas a $35^{\circ} \mathrm{C}$. A partir do crescimento positivo nos meios (ácido na base e alcalino no ápice para o meio Agar TSI e alcalino com ou sem produção de $\mathrm{H}_{2} \mathrm{~S}$ para o meio Agar LIA), uma nova alíquota foi retirada e semeada em Agar Triptona Soja (TSA), para a posterior realização dos testes bioquímicos adicionais e sorologia. As cepas foram identificadas por meio de chave de identificação bioquímica (urease, indol, fermentação de dulcitol, sacarose e lactose, vermelho de metila (VM), Voges Proskauer (VP), utilização do citrato e testes sorológicos polivalente e flagelar).

A suscetibilidade antimicrobiana das cepas de E. coli foi avaliada pelo método de difusão em 
discos segundo o Clinical and Laboratory Standards Institute (CLSI, 2005). A densidade do inóculo correspondeu ao tubo 0,5 da escala McFarland aferida em espectrofotômetro (Micronal, mod. B542). A suspensão bacteriana foi semeada em placas contendo Agar Mueller-Hinton com auxílio de swabs estéreis e adicionados os discos de antimicrobianos. As placas foram incubadas a $35^{\circ} \mathrm{C}$ por 24 horas. A leitura dos halos de inibição de crescimento foi realizada usando paquímetro digital. Os perfis de resistência e sensibilidade foram estabelecidos de acordo com o CLSI. Os antimicrobianos testados foram: ácido nalidíxico (30 $\mu \mathrm{g})$, ampicilina $(10 \mu \mathrm{g})$, gentamicina $(100 \mu \mathrm{g})$, imipenem $(10 \mu \mathrm{g})$, tetraciclina $(30 \mu \mathrm{g})$, amicacina $(30 \mu \mathrm{g})$, eritromicina $(15 \mu \mathrm{g})$ e cefalotina $(30 \mu \mathrm{g})$.

O índice de múltipla resistência antimicrobiana (MAR) foi utilizado para determinação da múltipla resistência, que é calculada dividindo o número de antimicrobianos ao qual o isolado foi resistente pelo número de antibióticos aos quais os isolados foram expostos. Índice MAR acima de 0,25 caracteriza multirresistência (KRUMPERMAN, 1983).

As cepas submetidas ao teste de antibiograma que apresentaram perfil de resistência aos antibióticos foram submetidas ao teste de cura plasmidial, realizada de acordo com Molina-aja et al. (2002).
Para a determinação da umidade usou-se a técnica gravimétrica, com secagem da amostra em estufa $\left(100^{\circ} \mathrm{C} \pm 5\right)$, baseado na remoção de água por aquecimento (AOAC, 1997). O teor de cloreto de sódio foi determinado pelo método titulométrico por meio da precipitação de íons $\mathrm{Cl}^{-}$com formação de sais de prata insolúveis (AOAC, 1997). A atividade de água $\left(\mathrm{A}_{\mathrm{w}}\right)$ foi realizada utilizando-se aparelho AQUALAB (Decagon Devices, Washington, USA). Todas as amostras foram realizadas em triplicata.

Os dados obtidos foram submetidos à análise de variância, utilizando o Programa SISVAR 5.1 e, para a comparação das médias dos tipos de estabelecimentos comerciais (supermercados, minimercados, açougues e boxes) quanto à contagem de micro-organismos, foi utilizado o Teste de Tukey (5\% de Probabilidade) (FERREIRA, 2008).

\section{Resultados e Discussão}

Na Tabela 1 são apresentados os resultados das análises de cloreto, $\mathrm{A}_{\mathrm{w}}$ e umidade na carne de sol. O baixo teor de sal e alta umidade e atividade de água no produto não são suficientes para manter a estabilidade do alimento, permitindo o crescimento microbiano.

Tabela 1. Resultados do teor de umidade, Atividade de água $\left(\mathrm{A}_{\mathrm{w}}\right)$ e cloreto na carne de sol comercializada em diferentes estabelecimentos em Cruz das Almas-BA.

\begin{tabular}{lcccccccccc}
\hline $\begin{array}{c}\text { Estabelecimentos } \\
\text { (n) }\end{array}$ & \multicolumn{3}{c}{ Umidade (\%) } & \multicolumn{2}{c}{ Teor de cloreto (\%) } & \multicolumn{2}{c}{ Atividade de água } \\
\hline & Mínimo & Máximo & Média & Mínimo & Máximo & Média & Mínimo & Máximo & Média \\
\hline Supermercados (4) & 67,54 & 74,09 & $70,34 \mathrm{~b}$ & 3,47 & 4,06 & $3,47 \mathrm{a}$ & 0,87 & 0,95 & $0,90 \mathrm{a}$ \\
Mini-mercados (3) & 69,31 & 74,69 & $72,16 \mathrm{~b}$ & 3,16 & 3,98 & $3,70 \mathrm{a}$ & 0,87 & 0,95 & $0,90 \mathrm{a}$ \\
Açougue (3) & 69,62 & 71,01 & $70,29 \mathrm{~b}$ & 3,22 & 4,16 & $3,76 \mathrm{a}$ & 0,88 & 0,95 & $0,91 \mathrm{a}$ \\
Mercado (2) & 56,37 & 71,01 & $58,92 \mathrm{a}$ & 3,22 & 5,89 & $4,95 \mathrm{a}$ & 0,88 & 0,93 & $0,90 \mathrm{a}$ \\
\hline
\end{tabular}

Médias na mesma coluna seguidas de letras diferentes apresentam diferença significativamente estatística pelo teste de Tukey (p $<0,05)$.

Fonte: Elaboração dos autores. 
Os manipuladores e comerciantes dos estabelecimentos afirmam que o teor de sal na carne de sol varia entre 5,0 e 6,0\%. Apenas uma amostra proveniente do Mercado esteve dentro desse intervalo, tendo as demais amostras apresentado um teor de sal inferior, não havendo diferença estatística $(p>0,05)$ entre os estabelecimentos. Este fato chama a atenção, uma vez que a maioria dos micro-organismos, patogênicos e deteriorantes são capazes de se desenvolverem em substratos com teores de sal inferiores a 10\% (COSTA; SILVA, 1999). Isso ocorre porque a carne de sol é norteada por uma tecnologia rudimentar, não existindo um regulamento técnico que padronize a sua composição centesimal, e parâmetros importantes como umidade e concentração de sal ainda são determinados por critérios aleatórios no processo de fabricação (LIMA, 2006).

Quanto a umidade, os valores encontrados são muito próximo ao da carne in natura, que varia entre 70 a 75\% (SOUSA et al., 2006). A elevada umidade está relacionada à baixa concentração de sal utilizado no processo da salga da carne de sol, bem como a não exposição ao sol durante o processo de secagem, ou quando acontece, a exposição é feita no início da manhã, ou no final da tarde, por períodos relativamente curtos, insuficientes para promover a desidratação do produto (COSTA et al., 2006).

Os valores da $A_{w}$ da carne de sol apresentaram uma amplitude de 0,87 a 0,95. Lira e Shimokomaki (1998) estabeleceram uma $\mathrm{A}_{\mathrm{w}}$ de 0,92 para a carne de sol. Considerando que a média da $\mathrm{A}_{\mathrm{w}}$ na carne de sol estudada foi de 0,90 as amostras se encontraram próximas ao valor recomendado. Entretanto, a elevada $\mathrm{A}_{\mathrm{w}}$ da carne de sol diminui a vida de prateleira do produto quando comparada ao jerked beef e ao charque $\left(\mathrm{A}_{\mathrm{w}} 0,70-0,80\right)$ (SHIMOKOMAKI; FRANCO; BISCONTINI, 1998).

Nummer et al. (2004) relataram a sobrevivência de E. coli O157, Salmonella, S. aureus e L. monocytogenes em carnes preparadas, com atividade de água dentro da faixa encontrada na carne de sol.

$\mathrm{Na}$ Tabela 2 são apresentados os resultados das análises microbiológicas nas amostras de carne de sol. Em virtude da legislação brasileira não especificar limites para a carne de sol, usouse como parâmetros os valores estipulados para produtos cárneos maturados como presuntos crus, salames, linguiças dessecadas, charque, jerked beef e similares (BRASIL, 2001).

Tabela 2. Média da contagem microbiana na carne de sol obtida em diferentes estabelecimentos em Cruz das AlmasBa.

\begin{tabular}{|c|c|c|c|c|}
\hline $\begin{array}{l}\text { Estabelecimentos } \\
\text { (número) }\end{array}$ & $\begin{array}{l}\text { Mesófilos } \\
\text { (UFC. }^{-1} \text { ) }\end{array}$ & $\frac{\text { Staphylococcus ssp. }}{\left(\text { UFC. }^{-1}\right)}$ & $\frac{{\text { Coliformes a } 35^{\circ} \mathrm{C}}_{\left(\text {NMP.g- }^{1}\right)}}{}$ & $\frac{\text { Coliformes a } 45^{\circ} \mathrm{C}}{\left(\text { NMP.g- }{ }^{1}\right)}$ \\
\hline Supermercados (4) & $2,7 \times 10^{6} \mathrm{a}$ & $2,7 \times 10^{6} \mathrm{a}$ & $2,7 \times 10^{2} \mathrm{a}$ & $3,0 \times 10^{1} \mathrm{a}$ \\
\hline Mini-mercados (3) & $5,5 \times 10^{7} \mathrm{ab}$ & $3,0 \times 10^{8} \mathrm{a}$ & $4,1 \times 10^{4} \mathrm{ab}$ & $3,7 \times 10^{4} \mathrm{a}$ \\
\hline Açougue (3) & $1,3 \times 10^{8} \mathrm{~b}$ & $2,1 \times 10^{8} \mathrm{a}$ & $1,1 \times 10^{5} \mathrm{~b}$ & $4,1 \times 10^{4} \mathrm{a}$ \\
\hline Mercado (2) & $1,4 \times 10^{8} \mathrm{~b}$ & $1,2 \times 10^{8} \mathrm{a}$ & $5,6 \times 10^{4} \mathrm{ab}$ & $5,5 \times 10^{4} \mathrm{a}$ \\
\hline
\end{tabular}

Médias na mesma coluna seguidas de letras diferentes apresentam diferença significativamente estatística pelo teste de Tukey ( $\mathrm{p}$ $<0,05)$.

Fonte: Elaboração dos autores. 
No Brasil, não há legislação para a contagem de micro-organismos mesófilos nos alimentos, entretanto, sua detecção é importante porque mesmo que os patógenos estejam ausentes e que não tenham ocorrido alterações nas condições sensoriais do alimento, o número elevado de microorganismos indica insalubridade do alimento. Casos de toxinfecção alimentar por cepas mesófilas de Proteus, enterococos e Pseudomonas, que não são patogênicos, via alimento têm sido relatados (FRANCO; LANDGRAF, 2008). De acordo com a literatura contagens acima de $10^{5} \mathrm{UFC}^{-g^{-1}}$ são consideradas impróprias para o consumo humano (COSTA; SILVA, 2001). Dainty e Mackey (1992) relataram que contagens microbianas na superfície da carne de $10^{-7}$ a $10^{-8}$ UFC.g. ${ }^{-1}$ são suficientes em promover alterações como odor acentuado, descoloração e limosidade superficial.

A presença de mesófilos por estabelecimento apresentou diferença estatística significativa ( $p$ $<0,05$ ) (Tabela 2). Essa diferença é atribuída a vários fatores, como a qualidade da matéria prima, higienização inadequada de utensílios e equipamentos, mão de obra não especializada e processamento inadequado da carne de sol. Os supermercados mesmo apresentando falhas, ainda foram os que melhor se adequavam às exigências legais (MIRANDA; EVANGELISTA-BARRETO, 2012).

Nos açougues e boxes do mercado, a manipulação do produto é intensa, além de ser mantida a temperatura ambiente (média de $25^{\circ} \mathrm{C}$ ). Nos supermercados e minimercardos o produto é comercializado sob refrigeração, embora, não haja uma aferição periódica da temperatura nos balcões de refrigeração. De acordo com a Portaria ${ }^{\circ} 304$ do Ministério da Agricultura (BRASIL, 1996) é exigida que toda a carne colocada à venda, deva sair dos abatedouros ou centrais de desossa já preparada em seus diversos cortes, além de devidamente embalada, proporcionando maior período de tempo de comercialização. No varejo, a carne deve ser acondicionada a temperatura de até $7^{\circ} \mathrm{C}$, como forma de promover maior segurança ao consumidor (OLIVEIRA et al., 2008).

Para os demais bioindicadores, apenas para coliformes a $35^{\circ} \mathrm{C}$ foi observada diferença significativa $(\mathrm{p}<0,05)$ entre os estabelecimentos (Tabela 2). A legislação brasileira também não estabelece limites para os coliformes a $35^{\circ} \mathrm{C}$. Semelhante aos mesófilos a elevada carga microbiana dessas bactérias indica insalubridade do alimento. Para os coliformes a $45^{\circ} \mathrm{C}, 58,33 \%$ das amostras se encontravam acima do limite preconizado na legislação $\left(10^{3}{\mathrm{NMP} . g^{-1}}^{-1}\right)(B R A S I L$, 2001).

Staphylococcus coagulase positiva não foi observada, estando de acordo com os padrões legais vigentes para este patógeno, embora, elevadas contagens de Staphylococcus spp. foram observadas $\left(10^{6}-10^{8}\right.$ UFC. $\left.^{-1}\right)$ (Tabela 2). Não houve diferença significativa $(\mathrm{p}>0,05)$ na contagem de Staphylococcus spp. nas amostras dos diferentes estabelecimentos. Costa e Silva (2001) ao analisarem carne de sol submetida a baixas concentrações de cloreto, provenientes de estabelecimentos inspecionados e não inspecionados, encontraram em ambos os grupos, elevadas contagens de Staphylococcus spp. Esse gênero inclui mais de 30 espécies, e embora a produção de enterotoxinas esteja normalmente associada a $S$. aureus, algumas espécies que são coagulase negativa, também já foram relatados em surtos alimentares (SANTANA et al., 2010).

Escherichia coli foi observada em 83,33\% das amostras analisadas, sendo $100 \%$ nas amostras provenientes dos açougues e mercado (Figura 1). Nesses estabelecimentos, além de um mini-mercado, a carne de sol é comercializada à temperatura ambiente, sobre balcão ou penduradas, sem nenhum tipo de embalagem ou proteção. O fácil acesso ao produto pelos consumidores também constitui um fator na contaminação do alimento. Escherichia coli não é permitida nos alimentos, mesmo em pequenas quantidades, visto que algumas cepas têm sido envolvidas em surtos de gastroenterites severas (FRANCO; LANDGRAF, 2008). 
Figura 1. Presença de Escherichia coli e Salmonella na carne de sol obtida em diferentes estabelecimentos em Cruz das Almas-Ba.

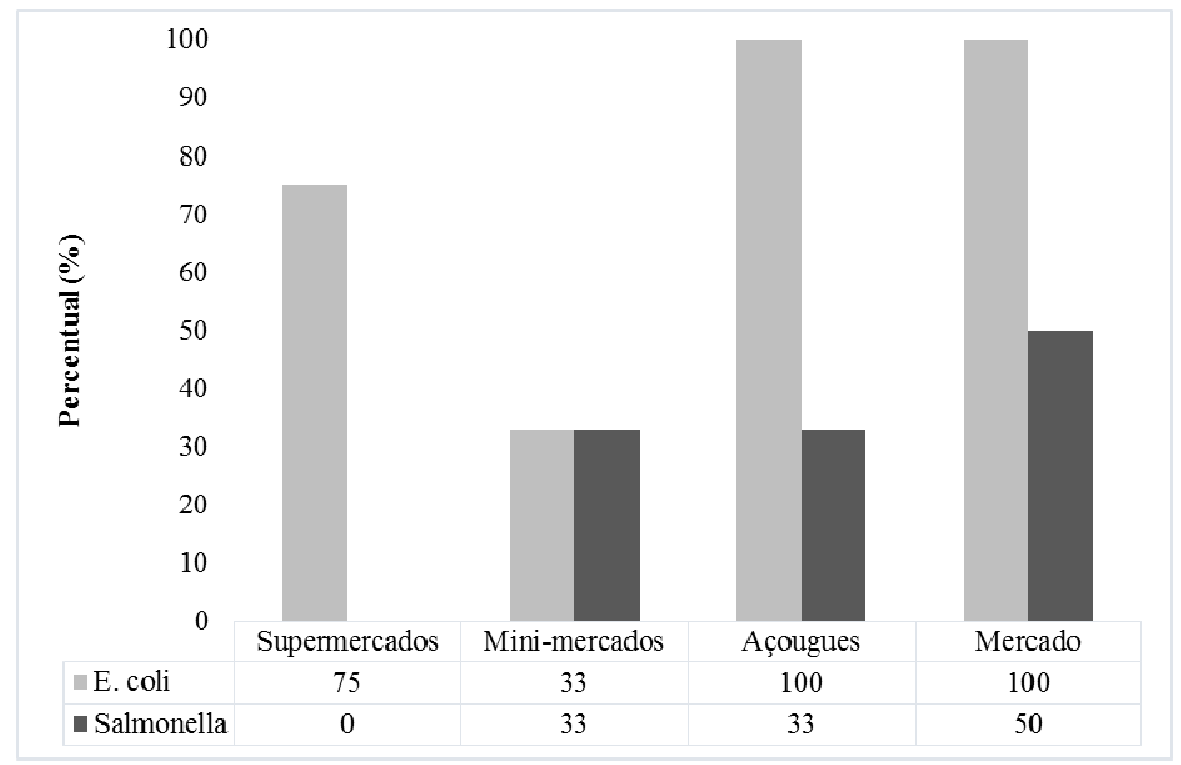

Fonte: Elaboração dos autores.

Salmonella foi isolada em amostras de três estabelecimentos, casas de açougue, minimercados e mercado municipal (Figura 1), sendo identificadas as espécies $S$. enterica subsp. enterica (3) e S. enterica subsp. indica. A Resolução $n^{\circ} 12$ da ANVISA (BRASIL, 2001) preconiza ausência de Salmonella em $25 \mathrm{~g}$ da amostra de carne maturada. A má qualidade da carne de sol pode estar relacionada à contaminação da matéria prima em sua origem, ou seja, animais abatidos em frigoríficos da região, além de relatos de abates clandestinos na cidade, em virtude da falta de fiscalização sanitária regular. Tudo isso é agravado quando existe a presença de roedores uma vez que estes são importantes animais portadores de Salmonella spp., eliminando o agente para o ambiente, juntamente com suas fezes (MENUCCI al., 2010). Segundo dados do MMWR (2013) nos Estados Unidos dos 29.444 surtos relacionados a alimentos, Salmonella resultou em 49\% das hospitalizações, seguido de E. coli $\mathrm{O} 157$ com $16 \%$.
$\mathrm{Na}$ Tabela 3 são apresentados os resultados do teste de suscetibilidade aos antimicrobianos para os isolados de Salmonella e E. coli. O perfil de suscetibilidade aos agentes antimicrobianos, classificados em seis grupos mostrou que $93,7 \%$ das cepas de Salmonella e E. coliapresentaram resistência a pelo menos um dos oito antimicrobianos testados. Foram consideradas tanto as estirpes resistentes como de resistência intermediária, visto que o uso de antimicrobianos com sensibilidade intermediária e classificados como sensíveis, somente faz seleção de cepas resistentes (CARVALHO et al., 2009). Imipenem foi o único antimicrobiano eficaz nas duas espécies estudadas, além de amicacina para Salmonella.

O imipenem é um antimicrobiano sintético, de amplo espectro de ação, que exerce ação bactericida, por inibir a síntese de parede celular dos microorganismos provocando lise osmótica. A amicacina se diferencia dos demais aminoglicosídeos por apresentar resistência à inativação pela maioria das enzimas produzidas pelas enterobactérias (TAVARES, 2009). 
Tabela 3. Perfil de suscetibilidade antimicrobiana das cepas de Salmonella e Escherichia coli obtidas em amostras de carne de sol, em Cruz das Almas-BA.

\begin{tabular}{|c|c|c|c|c|c|c|}
\hline \multirow[b]{2}{*}{ Antimicrobianos } & \multicolumn{3}{|c|}{ Escherichia coli (16) } & \multicolumn{3}{|c|}{ Salmonella (4) } \\
\hline & $\begin{array}{c}R \\
\mathbf{N}(\%) \\
\end{array}$ & $\begin{array}{c}I \\
\mathbf{N}(\%)\end{array}$ & $\begin{array}{c}S \\
\text { N (\%) }\end{array}$ & $\begin{array}{c}\mathbf{R} \\
\mathrm{N}(\%)\end{array}$ & $\begin{array}{c}I \\
\text { N }(\%)\end{array}$ & $\begin{array}{c}S \\
N(\%)\end{array}$ \\
\hline \multicolumn{7}{|l|}{ Betalactâmicos } \\
\hline Ampicilina & $12(75)$ & 0 & $4(25)$ & 0 & $3(75)$ & $1(25)$ \\
\hline Imipenem & 0 & 0 & $16(100)$ & 0 & 0 & $4(100)$ \\
\hline Cefalotina & $10(62,5)$ & $6(37,5)$ & 0 & $4(100)$ & 0 & 0 \\
\hline \multicolumn{7}{|l|}{ Aminiglicosídeo } \\
\hline Gentamicina & $2(12,5)$ & $6(37,5)$ & $8(50)$ & 0 & $3(75)$ & $1(25)$ \\
\hline Amicacina & $9(56,2)$ & $5(31,2)$ & $2(12,5)$ & 0 & 0 & $4(100)$ \\
\hline \multicolumn{7}{|l|}{ Tetraciclina } \\
\hline Tetraciclina & $9(56,2)$ & 0 & $7(43,7)$ & $4(100)$ & 0 & 0 \\
\hline \multicolumn{7}{|l|}{ Macrolideo } \\
\hline Eritromicina & $16(100)$ & 0 & 0 & $4(100)$ & 0 & 0 \\
\hline \multicolumn{7}{|l|}{ Quinolonas } \\
\hline Ac. nalidíxico & $5(31,2)$ & $1(6,2)$ & $10(62,2)$ & $4(100)$ & 0 & 0 \\
\hline
\end{tabular}

R: Resistência, I: Resistência intermediária e S: Sensível. N: número

Fonte: Elaboração dos autores.

Cepas com elevada resistência à tetraciclina, eritromicina, ac. nalidíxico e cefalotina, sugere que a utilização de antimicrobianos, principalmente de amplo espectro de ação, contribui para o aparecimento da resistência (VIEIRA et al., 2010). Ribeiro, Kellermann e Fittéli (2006) relataram elevada resistência de $S$. enterica subesp. entérica a tetraciclina e ao ac. nalidíxico. Costa et al. (2006) estudando E. coli isoladas em criatórios suínos no sul do Brasil, observaram resistência à tetraciclina em $88,6 \%$ dos isolados.

Resistência às tetraciclinas ocorre mais frequentemente devido a aquisição de plasmídios ou transpossons (ALTERTHUM, 2008), em virtude da ampla variedade de determinantes genéticos (VIEIRA et al., 2010), ou por genes cromossômicos, resultantes de mutação (TAVARES, 2009). O ác. nalidíxico é uma quinolona de primeira geração com ação somente em bacilos gram-negativos entéricos. A resistência adquirida às quinolonas, tem origem cromossômica (LIMA et al., 2006), tendo emergido como um importante problema de saúde pública, resultante da sua livre utilização em processos industriais de produção animal (JACOBY,
2005). O ac. nalidíxico tem ampla utilização no tratamento de doenças do trato urinário causadas por enterobactérias, bem como na terapêutica de infecções por Shiguella. Juntamente com a cefalotina (cefalosporina de primeira geração) tende a desenvolver resistência dentre os antimicrobianos de suas classes (SILVA; SANTOS; SCHMIDT, 2008; TAVARES, 2009).

Em bovinos de corte criados em sistema extensivo, o uso de antimicrobianos é realizado sem controle rigoroso, ocorrendo geralmente, em bezerros doentes com diarréias e pneumonias, ou mesmo em animais que apresentam febre ou lesões específicas (TAVARES, 2009).

Perfil de multiresistência foi observado em $100 \%$ dos isolados de Salmonella e em $87,5 \%$ de $E$. coli (Tabela 4). Salmonella apresentou índice MAR (Múltipla Resistência a Antimicrobianos) igual a 0,50, ou seja, resistência associada a quatro dos oito antimicrobianos testados. Em Escherichia coli o índice MAR variou de 0,25 a 0,62 (Tabela 4). De acordo com a literatura, tem havido um crescente aumento na multirresistência de $E$. coli isoladas de vários ecossistemas (VIEIRA et al., 2010). 
Tabela 4. Índice de múltipla resistência aos antimicrobianos (MAR) e perfil de resistência plasmidial das cepas de Salmonella e Escherichia coli isoladas de amostras de carne de sol comercializadas em Cruz das Almas-BA.

\begin{tabular}{cccc}
\hline Cepas & Antimicrobianos & MAR (\%) & Resistência Plasmidial \\
\hline M3 & ERI, NAL, TET, CFL & 0,50 & ERI \\
I1, G2 e G1 & ERI, NAL, TET, CFL & 0,50 & - \\
\hline \multicolumn{1}{c}{ Escherichi coli } & \multicolumn{2}{c}{ ERI } \\
J2 & ERI, NAL, TET, AMP, CFL & 0,62 & TET \\
G5 & ERI, NAL, TET, AMP, CFL & 0,62 & NAL, AMP \\
C5 & ERI, NAL, TET, AMP, CFL & 0,62 & - \\
G6 & ERI, TET, AMP, CFL, AMI & 0,62 & - \\
C1 e D1 & ERI, AMP, CFL, AMI & 0,50 & - \\
F4 & ERI, TET, AMP, CFL & 0,50 & GEN \\
L4 & ERI, GEN, TET, AMP & 0,50 & AMP \\
F1 & ERI, AMP, CFL & 0,37 & - \\
M1 & ERI, NAL, AMP & 0,37 & - \\
C3 & ERI, TET, CFL & 0,37 & - \\
I2 & ERI, GEN, AMP & 0,37 & - \\
H1 & ERI, CFL, AMP & 0,37 & - \\
\hline
\end{tabular}

Nota: $\mathrm{AMP}=$ Ampicilina; ERI= Eritromicina; GEN = Gentemicina; $\mathrm{IPM}=$ Imipenem; $\mathrm{NAL}=$ Ácido nalidíxico; $\mathrm{TET}=$ Tetraciclina; $\mathrm{CFL}=$ Cefalotina; $\mathrm{AMI}=$ Amicacina.

Fonte: Elaboração dos autores.

As cepas de Salmonella apresentaram um perfil de resistência associado a genes cromossômicos, uma vez que a resistência não foi perdida após o processo de cura. Para E. coli resistência mediada por plasmidios foi observada em cinco dos antimicrobianos (Tabela 4). A resistência nas bactérias tem preocupado os cientistas visto que bactérias sensíveis podem receber genes cromossômicos mutantes de bactérias resistentes, por meio de processos de transformação, conjugação e transdução (ALTERTHUM, 2008).

Ensaios realizados com cepas resistentes de Salmonella em frango de corte mostraram que os determinantes de resistência residem na conjugação de plasmídeos ou transposons e que os determinantes de resistência eram rapidamente transferidos entre espécies diferentes e mesmo entre gêneros diferentes (COSTA et al., 2006).

O elevado percentual de cepas de E. coli resistentes associada a dois ou mais antimicrobianos pode está ligado a fenômenos de pressão seletiva, que atuariam favorecendo a instalação, manutenção e propagação de características de resistência entre as populações bacterianas (VIEIRA et al., 2010). A presença de bactérias resistentes aos antimicrobianos é preocupante por dificultar o tratamento de doenças em animais e humanos, agravando os quadros clínicos curáveis (MOTA et al., 2005). Além disso, produtos de origem animal é uma importante fonte de $E$. coli como fonte de contaminação fecal. Esses micro-organismos e seus genes de resistência antimicrobiana podem ser transmitidos aos humanos se os alimentos forem mal cozidos (VAN et al., 2008). Por outro lado, novos agentes antimicrobianos que são desenvolvidos, tendem a ser mais caros e mais tóxicos que os utilizados anteriormente nos tratamentos de infecções, o que reforça a necessidade de adoção de medidas que controlem a disseminação de genes de resistência, visando à redução na sua circulação. 


\section{Conclusões}

Entre os estabelecimentos estudados, os supermercados apresentaram as melhores condições higiênica sanitária da carne de sol. Nos demais estabelecimentos se observou padrões microbiológicos insatisfatórios, com elevada carga microbiana de micro-organismos mesófilos aeróbios, presença de Salmonella e Escherichia coli.

$A$ variação nos teores de umidade, $A_{w}$ e cloreto de sódio mostra a necessidade de parâmetros que padronizem o processamento da carne de sol, visto que o teor de sal encontrado é insuficiente para exercer ação inibidora no crescimento microbiano, principalmente quando se tem um elevado percentual de cepas com multiresistência antimicrobiana.

\section{Agradecimentos}

Os autores agradecem ao Prof. Antônio Augusto Oliveira Fonseca pelo auxilio nas análises de atividade de água.

\section{Referências}

ALTERTHUM, F. Mecanismo de ação dos antibacterianos e mecanismo de resistência. In: TRABULSI, L. R.; ALTHERNUM, F. (Org.). Microbiologia. São Paulo: Atheneu, 2008. v. 1, p. 67-84.

ASSOCIATION OF OFFICIAL ANALYTICAL CHEMISTS - AOAC. Official methods of analysis. 16. ed. 16. ed. 3. rev. Gaitherburg: Published by AOAC International, 1997. v. 2, cap. 32, p. 1-43.

BRASIL. Agência Nacional de Vigilância Sanitária (ANVISA). Resolução RDC 12, de 02 de janeiro de 2001. Regulamento técnico sobre padrões microbiológicos para alimentos. Diário Oficial [da] União, Brasília, DF, 02 jan. 2001. Seção 1. p. 1-48.

Ministério da Agricultura, Pecuária e do Abastecimento. Portaria n³04 de 22 de abril de 1996. Introduz modificações e progressivas para que se alcancem avanços em termos higiênicos, sanitários e tecnológicos na distribuição e comercialização da carne bovina, bubalina e suína, visando principalmente à saúde do consumidor. Diário Oficial [da] União, Brasília, DF, 22 abr. 1996. Seção 1, p. 60.
CARVALHO, F. C.; EVANGELISTA-BARRETO, N. S.; REIS, C. M. F.; HOFER, E.; VEIREIRA, R. H. S. F. Susceptibilidade antimicrobiana de Salmonella spp. isoladas de fazendas de carciniculturas no Estado do Ceará. Revista Ciência Agronômica, Fortaleza, v. 40, n. 4, p. 549-556, 2009.

CLINICAL LABORATORY STANDARDS INSTITUTE - CLSI. Performance Standards for antimicrobial susceptibility testing. Twentieth Informational Supplement, M100-S20. Wayne, PA: CLSI, 2005.

COSTA, E. L.; SILVA, J. A. Avaliação microbiológica da carne de sol elaborada com baixos teores de cloreto de sódio. Ciência e Tecnologia de Alimentos, Campinas, v. 21, n. 2, p. 149-135, 2001.

COSTA, E. L.; SILVA, J. A. Qualidade sanitária de carne de sol comercializada em açougues e supermercados de João Pessoa-PB. Boletim do Centro de Pesquisa de Processamento de Alimentos, Curitiba, v. 17, n. 2, p. 137 144, 1999.

COSTA, M.; SILVA, M. S.; SPRICIGO, D. A.; MITT, N. M.; MARCHIORO, S. B.; VARGAS, A. P. Caracterização epidemiológica, molecular e perfil de resistência aos antimicrobianos de Escherichia coli isoladas de criatórios suínos do sul do Brasil. Pesquisa Veterinária Brasileira, Rio de Janeiro, v. 26, n. 1. p. 5-8, 2006.

DAINTY, R. H.; MACKEY, B. M. The relationship between the phenotypic properties of bacteria from chill-stored meat and spoilage processes. Journal of Applied Microbiology, Oxford, v. 73, p. 103-114, 1992. Supplement 21.

FERREIRA, D. F. SISVAR: um programa para análises e ensino de estatística. Revista Symposium, Lavras, v. 6, n. 1, p. 36-41, 2008.

FRANCO, B. D. G. M.; LANDGRAF, M. Microbiologia dos alimentos. São Paulo: Atheneu, 2008. 181p.

INTERNATIONAL COMMISSION ON MICROBIOLOGICAL SPECIFICATIONS FOR FOODS - ICMSF. Use of epidemiologic data to measure the impact of food safety control programs. Food Control, Guildford, v. 17, n. 10, p. 825-37, 2006.

JACOBY, G. A. Mechanisms of resistence to quinolones. Clinical infectious Diseases, Chicago, v. 41, p. S120-S126, 2005. Supplement 2.

KRUMPERMAN, P. H. Multiple antibiotic resistance indexing of Escherichia coli to identify high-risk sources of fecal contamination of foods. Applied and Environmental Microbiology, Washington, v. 46, n. 1, p. 165-170, 1983. 
LIMA, R. M. S.; MARCIANO, M. A. M.; ATUI, M. B.; POLI NETO, A.; GERMANO, P. M. L. Resistência a antimicrobianos de bactérias oriundas de ambiente de criação de filés de tilápias. Ciência e Agrotecnologia, Lavras, v. 30, n. 1, p. 126-132, 2006.

LIRA, G. M.; SHIIMOKOMAKI, M. Parâmetros de qualidade da carne de sol e dos charques. Higiene Alimentar, São Paulo, v. 12, n. 58, p. 33-35, 1998.

MENUCCI, T. A.; MARCIANO, M. A. M.; ATUI, M. B.; POLI NETO, A.; GERMANO, P. M. L. Avaliação da contaminação por matérias estranhas em carne de sol comercializada em "casas do norte". Revista do Instituto Adolfo Lutz, São Paulo, v. 69, n. 1, p. 47-54, 2010.

MIRANDA, P. C.; EVANGELISTA-BARRETO, N. S. Avaliação higiênico-sanitária de diferentes estabelecimentos de comercialização da carne-de-sol no município de Cruz das Almas-BA. Revista Caatinga, Mossoró, v. 25, n. 2, p. 166-172, 2012.

MMWR. Morbidity and mortality weekly report. Surveillance for foodborne disease outbreaks - United States, 2009-2010. Weekly, v. 62, n. 3, p.41-47, 2013. Disponível em: <http://www.cdc.gov/mmwr/preview/ mmwrhtml/mm6203a1.htm>. Acesso em: 26 fev. 2012.

MOLINA-AJA, A.; GARCÍA-GASCA, A.; ABREUGROBOIS, A.; BOLÁN-MEJÍA, C.; ROQUE, A.; GOMEZ-GIL, B. Plasmid profiling and antibiotic resistance of Vibrio strains isolated from cultured penaeid shrimp. FEMS Microbiology Letters, Amsterdam, v. 213, n. 1, p. 7-12, 2002.

MOTA, R. A.; SILVA, K. P. C.; FREITAS, M. F. L.; PORTO, W. J. N.; SILVA, L. B. G. Utilização indiscriminada de antimicrobianos e sua contribuição a multirresistência bacteriana. Brazilian Journal of Veterinary Research and Animal Science, São Paulo, v. 42, n. 6, p. 465-470, 2005.

NUMMER, B. A.; HARRISON, J. A.; HERRISON, M. A.; SOFOS, J. N.; ANDRESS, E. L. Effects of preparation methods on the microbiological safety of home-dried meat jerky. Journal Food Protection, Des Moines, v. 67, n. 10, p. 2337-2341, 2004.

OLIVEIRA, S.; SILVA, J. A.; MACIEL, J. F.; AQUINO, J. S. Avaliação das condições higiênico-sanitárias de carne bovina comercializada em supermercados de João Pessoa. Revista Alimentação e Nutrição, Araraquara, v. 19, n. 1, p. 61-66, 2008.

RIBEIRO, A. R.; KELLERMANN, L. R. S.; FITTÉLI, V. P. N. Resistência antimicrobiana em Salmonella entérica subesp. entérica sorovar Hadar isoladas de carcaças de frango. Arquivos do Instituto Biológico, São Paulo, v. 73, n. 3, p. 357-360, 2006.
SCHMIDT, V.; CARDOSO, M. R. I. Sobrevivência e perfil de resistência a antimicrobianos de Salmonella sp. isoladas em sistema de tratamento de dejetos de suínos. Ciência Rural, Santa Maria, v. 33, n. 5, p. 881-888, 2003.

SHIMOKOMAKI, M.; FRANCO, B. D. G. M.; BISCONTINI, T. M. Charqui meats are hurdle technology meat products. Food Reviews International, New York, v. 14, n. 4, p. 339-349, 1998.

SILVA, F. F. P.; SANTOS, M. A. A.; SCHMIDT, D. Resistência a antimicrobianos de Escherichia coli isolada de dejetos suínos em esterqueiras. Arquivo Brasileiro de Medicina Veterinária e Zootecnia, Belo Horizonte, v. 60, n. 3, p. 762-765, 2008.

SILVA, N.; SILVA, N.; JUNQUEIRA, V. C. A.; SILVEIRA, N. F. A.; TANIWAKI, M. H.; SANTOS, R. F. S.; GOMES, R. A. R. Manual de métodos de análise microbiológica de alimentos. 4. ed. São Paulo: Varela, 2007. $552 \mathrm{p}$.

SANTANA, E. H.W.; BELOTI, V.;ARAGON-ALEGRO, L. C.; MENDONÇA, M. B. O. C. Estafilococos em alimentos: artigo de revisão. Arquivos do Instituto Biológico, São Paulo, v. 77, n. 3, p. 545-554, 2010.

SOUSA, J. S.; BARRETO, L. C.; FERNANDES, M. V. M.; LEITE, A. B.; BURGHGRAVE, V. S.; RAMOS, J. C. Avaliação da qualidade higiênico-sanitária de frangos comercializados na cidade de Salvador-Bahia. Higiene Alimentar, São Paulo, v. 21, n. 150, p. 76-77, 2006.

TAVARES, W. Bactérias gram-positivas problemas: resistência do estafilococo, do enterococo e do pneumococo aos antimicrobianos. Revista Sociedade Brasileira de Medicina Tropical, Uberaba, v. 33, n. 3, p. 291-301, 2009.

VAN, T. T.; CHIN, J.; CHAPMAN, T.; TRAN, L. T.; COLOE, P. J. Safety of raw meat and shellfish in Vietnam: An analysis of Escherichia coli isolations for antibiotic resistance and virulence genes. International Journal of Food Microbiology, Amsterdam, v. 124, n. 3, p. 217-223, 2008.

VIEIRA, R. H. S. F.; VASCONCELOS, F. R.; REBOUÇAS, R. H.; EVANGELISTA-BARRETO, N. S.; SOUZA, O. V. Perfil de resistência antimicrobiana de Escherichia coli isoladas do açude Santo Anastácio, Ceará, Brasil. Arquivos do Instituto Biológico, São Paulo, v. 77, n. 3, p. 405-410, 2010.

VIGNOTO, V. K. C.; CARMO, L. G.; WOSIACKI, S. R. Efeito da maturação da carne na qualidade sanitária do jerked beef. Publicatio UEPG: Ciências Exatas e da Terra, Ciências Agrarias e Engenharias, Ponta Grossa, v. 16, n. 2, p. 89-95, 2010. 